\title{
El liderazgo en la producción automotriz mundial: Una historia de cambio en los 130 años de existencia de la industria.
}

\section{Leadership in Global Automotive Production: A History of Change in the Industry's 130 Years}

Giovanny Javier Alarcón Parra. ${ }^{1}$, Xavier Centeno Parra. ${ }^{2}$, Oswaldo Villacrés Cáceres. ${ }^{3}$ \& Andrea Margarita Garrido Patrel. ${ }^{4}$

\begin{abstract}
.
DOI: https://doi.org/10.33262/concienciadigital.v3i3.1.1387
\end{abstract}

The purpose of this paper is to contribute to the knowledge of the history and evolution of the global automotive industry, the different actors and events that allowed different countries and their brands to be positioned in the leadership of the sector. From Karl Benz commercializing the first units at the end of the 19th century, to the start of Ford's mass production, which exponentially increased the production of American vehicles in favor of the North American country at the beginning of the 20th century and initiating, together with other producers, a period of more than half a century of predominance in production and exports at a global level; to the Asian automotive industry of the post Second World War that had in Japan its main exponent and with the capacity to compete and dispute the first place of the production and sales to achieve it in 2008; and finishing with the irruption of the Chinese automotive industry that applying different strategies located it as the first power in production and commercialization towards the second decade of the 21 st century. Towards the end, the Ecuadorian automotive market is analyzed in an analogous way, showing the same behavior of the industry at a global level, replicating the trends. With a vast analysis of specialized sources, publications and considering an extensive bibliographic documentation; this document contributes to the knowledge and understanding of the evolution of one of the most important, dynamic and influential economic sectors of the present time, and how the different crises and wars that occurred in the previous century modified the trends of production and sale of vehicles.

\footnotetext{
${ }^{1}$ Escuela Superior Politécnica de Chimborazo, Facultad de Administración de Empresas, Chimborazo Ecuador, galarcon@espoch.edu.ec

2 Escuela Superior Politécnica de Chimborazo, analista de evaluación, Chimborazo Ecuador, eduardo.centeno@espoch.edu.ec

${ }^{3}$ Escuela Superior Politécnica de Chimborazo, Facultad de Ciencias, Chimborazo Ecuador, ovillacres@espoch.edu.ec

${ }^{4}$ Universidad Nacional de Chimborazo, Carrera de Gestión Turística y Hotelera - Turismo, de la Facultad de Ciencias Políticas y Administrativas, andreapatrel@hotmail.com
} 
Key Words: Automotive industry, vehicles, automotive history, ecuadorian automotive market.

\section{Resumen}

El presente trabajo tiene como propósito contribuir al conocimiento de la historia y evolución de la industria automotriz mundial, los diferentes actores y sucesos que permitieron posicionar en el liderazgo del sector a distintos países y sus marcas. Desde Karl Benz comercializando las primeras unidades a finales del siglo XIX, pasando por la puesta en marcha de la producción en serie de Ford, que elevó exponencialmente la producción de los vehículos estadounidenses en favor del país norteamericano empezando el siglo XX e iniciando junto a otros productores una etapa de más de medio siglo de predominio en la producción y exportaciones a nivel global; a la industria automotriz asiática de la post segunda guerra mundial que tuvo en Japón su principal exponente y con la capacidad de competir y disputar el primer lugar de la producción y ventas para lograrlo en el 2008; y finalizando con la irrupción de la industria automotriz china que aplicando distintas estrategias le ubicaron como la primera potencia en producción y comercialización hacia la segunda década del siglo XXI. Hacia el final se analiza como de manera análoga el mercado automotriz ecuatoriano manifiesta el mismo comportamiento de la industria a nivel mundial replicando las tendencias. Con un vasto análisis de fuentes especializadas, publicaciones y considerando una amplia documentación bibliográfica; este documento aporta al conocimiento y comprensión de la evolución de uno de los sectores económicos más importantes, dinámicos e influyentes de la actualidad, y como las distintas crisis y guerras ocurridas en el siglo anterior modificaron las tendencias de producción y venta de vehículos.

Palabras Clave: Industria automotriz, vehículos, historia automotriz, mercado automotriz ecuatoriano.

\section{Introducción}

El vehículo es hoy en día en un artefacto fundamental en el desarrollo de las actividades del ser humano, en la actualidad es prácticamente imposible imaginar una vida sin ellos, ya sea para actividades laborales, familiares, de diversión y otras, se ha convertido en un bien de primera necesidad (Lolas, 2019) he imprescindible en las labores de la sociedad actual (Faes, 2016), en un artículo titulado «Manejando por Santiago: Explorando el uso de automóviles por parte de habitantes de bajos ingresos desde una óptica de movilidad sustentable 〉 el autor describe lo que a su consideración es la mecánica del funcionamiento de la sociedad actual y cuál es el papel del vehículo visto como tecnología del transporte:

"La movilidad espacial mediante el uso de tecnologías del transporte es central en el modo en que las personas viven los espacios urbanos contemporáneos. Desde el acceso al lugar de trabajo o estudio hasta las formas en las que se utiliza el tiempo libre, el habitar en la ciudad contemporánea está estructurado en torno a crecientes niveles de movimiento entre diversos lugares" (Ureta Icaza, 2009).

Para llegar a este punto, en que el vehículo paso de ser considerado un "artículo" de lujo y no fundamental en las actividades diarias hacia finales de los 1800, a ser un apoyo indispensable no 
solo para el desarrollo de la actividades personales sino de la sociedad actual y pilar de su aparato productivo, la industria automotriz tuvo que atravesar por diferentes procesos de transformación y adaptación a las complejas condiciones que el siglo XX presentó a esta naciente actividad empresarial, con la innovación como base de su crecimiento y posterior éxito, las actividades del sector automotriz cumplieron un papel muy relevante y en ocasiones crucial en el proceso de industrialización de muchos países (Mortimore \& Barron, 2005) y su posicionamiento en el liderazgo de la producción mundial.

Este documento describe la historia y evolución de la industria automotriz desde el enfoque del liderazgo que las distintas marcas de fabricantes otorgaron a sus países de origen ${ }^{5}$ y como ha ido cambiando a otras naciones y regiones del mundo a lo largo de 130 años de existencia $\ll 1889$ 2019 》. Aplicando la metodología descriptiva, bibliográfica e histórica se relatan los principales sucesos asociados la fabricación automotriz desde el inicio de la producción en serie en la Norteamérica de finales de los años 1800 e inicio de los 1900 con la empresa Ford como protagonista y precursora de la línea de ensamblaje en movimiento, y otras empresas que posicionaron a las marcas estadounidenses en el liderazgo mundial en la manufactura y consumo de vehículos; continua el análisis hacia la industria japonesa de la post-segunda guerra mundial, en particular la empresa Toyota que destronó a General Motors del primer lugar en la producción del mercado automotriz en los primeros años de la década del 2000 y le valió a Japón para superar a los Estados Unidos como nación productora y exportadora; se prosigue hasta nuestros días en que un país como China, considerado aún como una economía emergente ha tomado por asalto el liderazgo de la producción y comercialización de vehículos en la primera parte del siglo XXI, con un vertiginoso crecimiento de sus marcas nacionales y el posicionamiento en la preferencia de los consumidores actuales de los últimos años.

El propósito entonces es presentar todos los hechos acaecidos en el periodo de estudio y una línea secuencial de sucesos que permitan entender que los procesos de transformación siempre han estado presentes en una de las industrias más importantes de la sociedad actual, y comprender por qué de manera recurrente empresarios, políticos, medios de comunicación, publicaciones en redes sociales entre otras manifiestan el cambio de condiciones, marcas y preferencias de los clientes. Para cumplir este objetivo se ha realizado una revisión sistemática y exhaustiva de fuentes bibliográficas formales, con resultados de investigación de terceros e información de organizaciones oficiales de la industria automotriz que permitieron sustentar los hechos históricos aquí planteados; y empleado además fuentes especializadas del sector como revistas, periódicos y sitios electrónicos de reconocida reputación que aportaron información relevante para este trabajo. De manera adicional se presenta el mismo procedimiento de análisis aplicado al mercado automotor ecuatoriano y las conclusiones hacia el final del documento donde se recoge los principales hechos para emitir los criterios correspondientes. En definitiva,

\footnotetext{
${ }^{5}$ Las estructuras de mercado predominantes actualmente en las economías capitalistas son los oligopolios mundiales, los cuales se caracterizan más allá del pequeño número de firmas que comparten el poder de mercado colectivo, por la fuerte rivalidad entre sus miembros y la tendencia a establecer alianzas que trascienden las relaciones estables en la fijación de precios o niveles de producción (Chesnais,1994). Esta definición posibilita la coexistencia entre los grandes grupos dominantes y empresas medianas y pequeñas, en algunos casos (Lavarello, Bil, Vidosa, \& Langard, 2019).
} 
el presente trabajo aporta información valiosa que permite identificar la dinámica del sector automotriz, sus antecedentes y perspectivas de futuro.

\section{El nacimiento de una industria.}

A pesar de lo expresado en la primera parte de este documento, esta situación de tener al vehículo como eje fundamental de las actividades cotidianas no siempre fue así; la historia del automóvil se remonta a la Gran Bretaña y Estados Unidos de finales del siglo XVIII (Auto México, 2019), cuando el ser humano motivado por recorrer las distancias empleando cada vez un menor tiempo inventó el automóvil. Desde Joseph Cugnot, ingeniero francés que en 1771 desarrolló para la milicia un vehículo autónomo de tres ruedas (Clothier, Fulton, \& Walker, 2008); hasta Karl Benz que en 1889 ya "había capitalizado y vendido varios automóviles al público" (Auto México, 2019) dieron origen a la nobel industria automotriz, pero con productos destinados a personas con alta capacidad de adquisición.

Gráfico N 1: Afiche publicitario de Oldsmobile (1095)

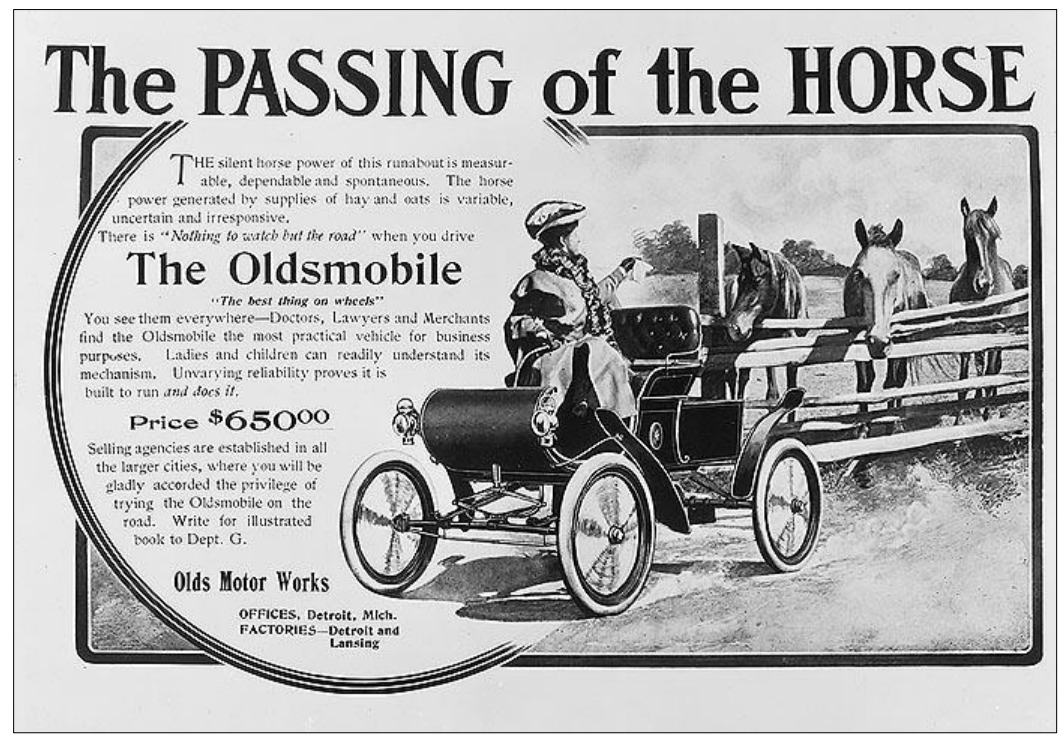

Fuente: Historia visual de la publicidad automotriz desde 1888 hasta 1919 (Univisión Communications Inc., 2016).

La publicidad de la gráfica 1 anuncia un automóvil Oldsmobile modelo 1905 e ilustra como el vehículo de motor deja atrás al caballo, un lujo que la compañía podría satisfacer por tan sólo “\$650” (Univisión Communications Inc., 2016); estos vehículos producidos de forma artesanal (Ortíz Villajos, 2001) eran construidos uno a la vez, con costos de producción altos que generaban un precio final de venta elevado y de difícil acceso para la clase media y baja de aquel entonces. Esta realidad cambio años más tarde cuando los vehículos llegaron a precios asequibles para los consumidores de clase media, motivada esta situación por el descenso y posterior estabilidad de los precios tras los ajustes alcistas de la crisis de postguerra de los años 1930 (Marco, 2002).

\section{El posicionamiento de la industria norteamericana en el liderazgo mundial}

Desde el inicio de la producción "en masa", los fabricantes estadounidenses acapararon el mercado mundial, sobre todo a partir de la implementación de la banda movible o línea de 
montaje; con esta innovación "Ford no sólo inició los procesos de fabricación masiva de productos estandarizados, dejando atrás la fabricación artesanal, sino que incrementó en mucho los volúmenes de producción y redujo los costos unitarios de producción" (Michael \& Faustino, 2005); hacia 1908 el modelo T de Ford Motor Company se vendía a un precio de 1000 dólares, en pocos años y con el empleo de las nuevas técnicas de producción su precio se abarató por debajo de los 300 dólares (Ruíz, 2001), llegando a un número cada vez mayor de clientes.

De esta forma, el inicio del siglo pasado trajo una revolución en la producción de vehículos (Michael \& Faustino, 2005), pero sobre todo posesionó a marcas y empresas como Ford y General Motors en la cima de la preferencia de los consumidores, logrando producir más de 4 millones de vehículos a finales de los años veinte, así, los fabricantes norteamericanos llegaron a disfrutar de una ventaja absoluta e indiscutible a nivel mundial (Ruíz, 2001), no así la industria europea que previo a los conflictos mundiales tuvo a países como Francia, Alemania y sobre todo Gran Bretaña en la capacidad de competir con los automóviles "made in USA" (Yáñez \& Badia-Miró, 2011), pero con el estallido de la primera guerra mundial en 1914 (Hernández, 2007), que obligó tanto a los países como a sus industrias orientar su producción a la provisión de materiales e insumos para la guerra; en particular la industria del acero gracias a la gran cantidad de ganancias que estas actividades les generaban (Mustoe, 2004), desviando su atención y prioridad que tenían por la fabricación de autos de consumo. Esta situación se mantuvo por más de dos décadas, tiempo en el cual una nueva contienda ecuménica tuvo lugar, la segunda guerra mundial entre 1939 a 1945 (Hernández, 2009).

El final de la década de los años 50s fue esencial para la industria automotriz norteamericana, se había transformado y superado a la producción de Gran Bretaña, Francia, Japón, Suecia y todas las demás naciones juntas (Anything About Cars), posicionando a nivel mundial lo que se le denominó como los "tres grandes", General Motors, Ford, y Chrysler; en esta misma década Ford y GM produjeron su vehículo número 50 millones. El gráfico 2 muestra la cantidad de vehículos producidos en Norteamérica entre los años 1951 a 2011.

Gráfico 2 Producción de vehículos entre 1951 a 2011 (en millones de unidades).

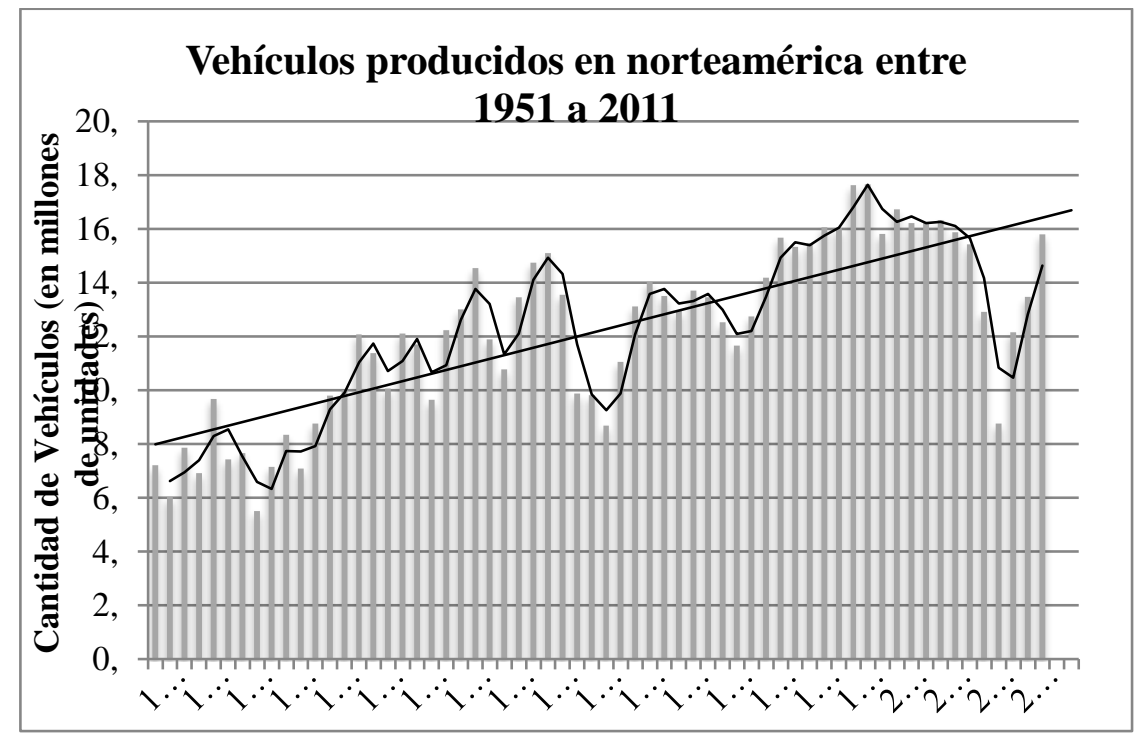

Fuente: Producción de vehículos norteamericanos desde 1950 a 2012 en base a (Statista, 2013). 
En la gráfica presentada también se puede observar como desde el año de 1951 hasta el 2011 existe una marcada tendencia de crecimiento en la producción de vehículos norteamericanos que se mantuvo durante todo el periodo con excepción de los años 1979 a 1983 en que el mundo salía de la denominada crisis del petroleó (Nicolás, 2013) producida entre 1973 a 1979 que afectó fundamentalmente a la industria del automóvil; y el año 2009 a causa de la crisis económica y financiera de impacto mundial (Rosenthal, 2010) originada en los Estados Unidos y conocida como la burbuja inmobiliaria (Daher, 2013) que golpeó fuertemente (Agencia EFE, 2017) al sector automotriz. Con estos hechos la "crisis mundial dejó al descubierto las debilidades técnicas y económicas que las empresas automotrices americanas acumularon a lo largo del tiempo" (Arenas Rosales, Vera Sanjuán, \& Soto Bustos, 2010).

\section{La toma del liderazgo de la industria asiática: Japón}

El auge de la producción y ventas de vehículos a nivel mundial y los altos niveles de rendimiento económico del sector en época de la post II guerra mundial auspició una agresiva estrategia de expansión del comercio del vehículo japonés; con el antecedente negativo de la participación del país asiático en la segunda guerra mundial, y la intervención norteamericana en los asuntos de estado como resultado de su victoria en la contienda (García, 2012), fueron entre otras las principales razones que revirtieron el manejo de la política exterior japonesa de la post-guerra (Murakami, 1995) que contribuyó a generar circunstancias favorables para el crecimiento del sector industrial en general, en el artículo «Las políticas gubernamentales de ciencia y tecnología en el Asia Pacífico en la posguerra: los casos de Japón y Corea del Sur 》 los investigadores al respecto de la situación del país posterior a la guerra señalan:

En los años setenta, Japón una vez recuperado de los estragos que había sufrido durante la Segunda Guerra Mundial y a partir del modelo democrático impuesto por Estados Unidos, tuvo las condiciones adecuadas para sentar las bases de desarrollo del país, que lo convertirían en una potencia económica y tecnológica mundial (Boncheva, et al. 2016).

Este escenario permitió a la industria japonesa desarrollarse y competir con los productores norteamericanos; un punto de inflexión se dio cuando en 1966 llegó el modelo Corolla a los concesionarios europeos, popularizándose rápidamente (Toyocosta, s.f.) entre los consumidores, conquistando su preferencia sobre modelos de similares características. En el inicio de la década de los años 70’s cuando la empresa Toyota introduce en el mercado estadounidense además del modelo Corolla, otros que se posicionan en el gusto y favoritismo de los consumidores, que motivados por las nuevas condiciones del entorno e influenciados principalmente por las consecuencias de la crisis del petróleo «1973-1979》 que encarecieron el mantenimiento de los vehículos norteamericanos, fueron entre otros el detonante de la verdadera expansión mundial del vehículo japonés y el declive de Estados Unidos como potencia hegemónica ante la eficacia del sistema de producción Toyota (Álvarez, 2013), el portal especializado Motor Historia resume esta época de la siguiente manera:

La expansión continuó a lo largo de la década de los setenta. Continua 《la empresa》 con esta política, nacen modelos como el Toyota Celica, un precioso cupé que sería todo un éxito de ventas. La llegada de los nuevos Toyota Corolla y Toyota Crown, ayudarían 
a que en 1972, llegar a los diez millones de unidades producidas. Debido a la crisis del petróleo de 1973, los consumidores de mercados como el norteamericano comenzaron a demandar automóviles más pequeños y frugales. Esto haría que las ventas de Toyota comenzaran a despegar, en gran medida gracias a sus modelos de tamaño reducido, económicos de mantener y bien realizados (Motor Historia).

Además de Toyota, empresas como Nissan, Mitsubishi, Honda, Suzuki, Mazda, Dahiatsu, Izuzu y Subaru se fortalecen en el mercado mundial en la década final de los años 90’s he inicios del siglo XXI, en este periodo y a pesar de un baja de ventas del sector, estas firmas siguen incrementando el número de unidades producidas a nivel mundial, cuentan con las materias primas de calidad y la infraestructura necesaria para su operación; además, aprovechan las facilidades e incentivos que gobiernos de diversos países ofrecen para la instalación de sus plantas de ensamble (Blanco Jiménez, Guerra Moya, \& Villalpando Cadena, 2007), reestructurando las estrategias de posicionamiento y comercialización de sus productos, la gráfica 3 muestra los niveles de producción en el periodo 1993 - 2006.

Gráfico No3 Principales Compañías Automotrices en Japón.

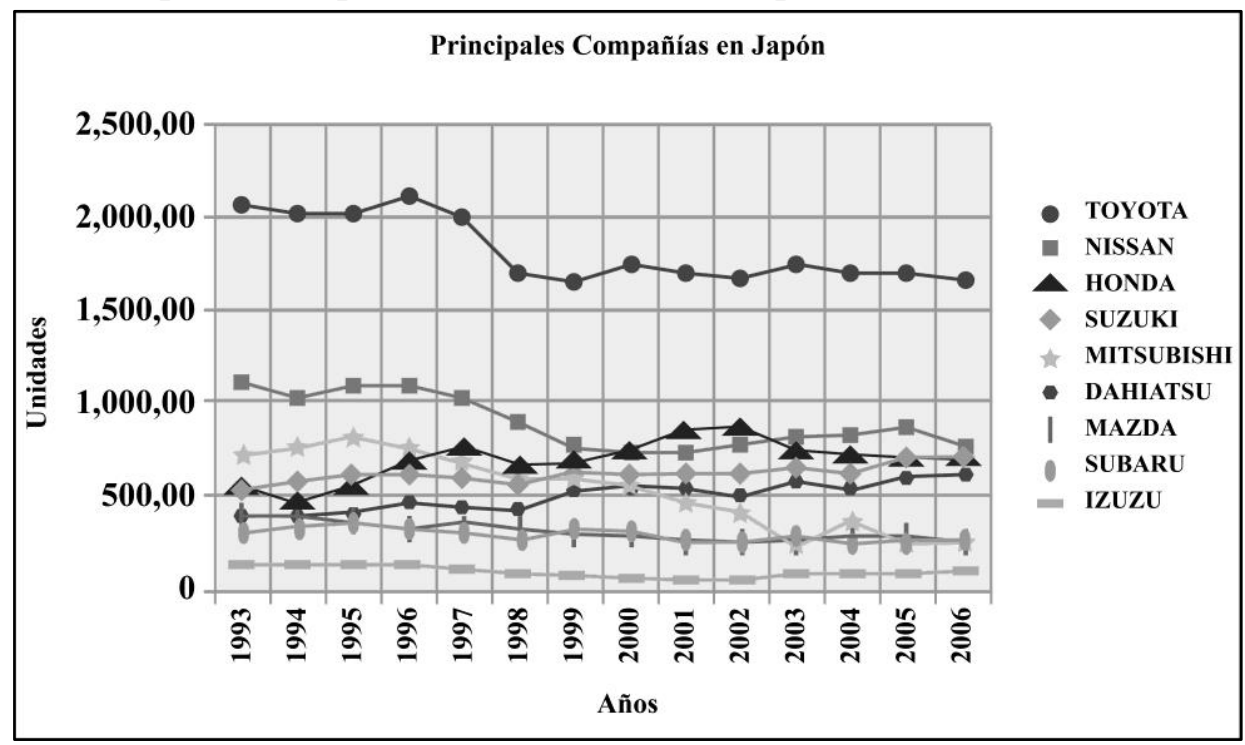

Fuente: Evolución de la Industria del Sector Automotriz en Japón, Crecimiento de las Empresas Japonesas en base a (Blanco Jiménez, Guerra Moya, \& Villalpando Cadena, 2007).

Consolidándose 《Japón》 a partir de estos hechos como uno de los países líderes en el contexto mundial, mantiene su crecimiento “... produciendo automóviles muy asequibles, fiables y populares a lo largo de la década de 1990, « de esta manera》 Japón se convirtió en el mayor país productor de automóviles del mundo en el año 2000" (Marcas de Coches, s.f.); en la misma línea, Toyota llega a superar a la estadounidense General Motors como el fabricante de automóviles más grande del mundo, esto en el primer trimestre de 2008; este hecho fue comunicado por el Diario El País de España, el cual informaba a sus lectores en la publicación del mismo año que "la japonesa Toyota ha desbancado a la estadounidense General Motors como fabricante mundial de automóviles en el primer trimestre del año, con 2,41 millones de vehículos vendidos por 2,25 de la estadounidense" (El País, 2008). 
La gráfica 4 permite observar el "desplome" de la venta de los vehículos norteamericanos desde el año 2007, en particular el año 2009 donde alcanza su punto más bajo.

Gráfico No4 Cantidad de vehículos norteamericanos comercializados entre 2003 a 2013 (en millones de unidades).

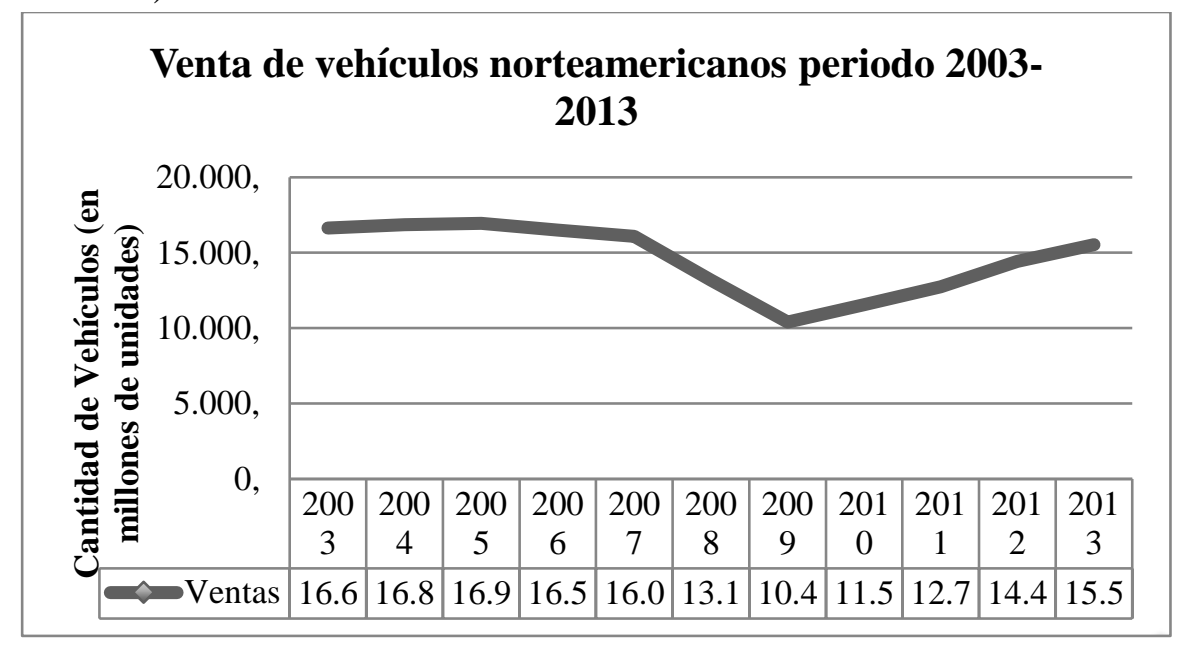

Fuente: Venta de vehículos en Estados Unidos periodo 1978-2018 en base a (Statista, 2019).

Paralelamente, el reporte de las exportaciones de vehículos japoneses en el año 2017 muestran un incremento por tercer año consecutivo, totalizando 4.71 millones de unidades comercializadas en el exterior, y las exportaciones de automóviles de pasajeros aumentaron $2.4 \%$ en relación al año 2016 con 4,22 millones de unidades, mientras que las exportaciones de camiones se registraron en 368,000 unidades y de autobuses en 119,000 unidades (Japan Automobile Manufacturers Association, Inc, 2018). La imagen de la gráfica 5 muestra parte del informe presentado por la Asociación Japonesa de Fabricantes de Automóviles en el año 2008, en donde se puede observar las tendencias de crecimiento de las exportaciones de vehículos por tipo.

Gráfico 5. Reporte de las exportaciones de vehículos japoneses en el año 2017 por tipo.

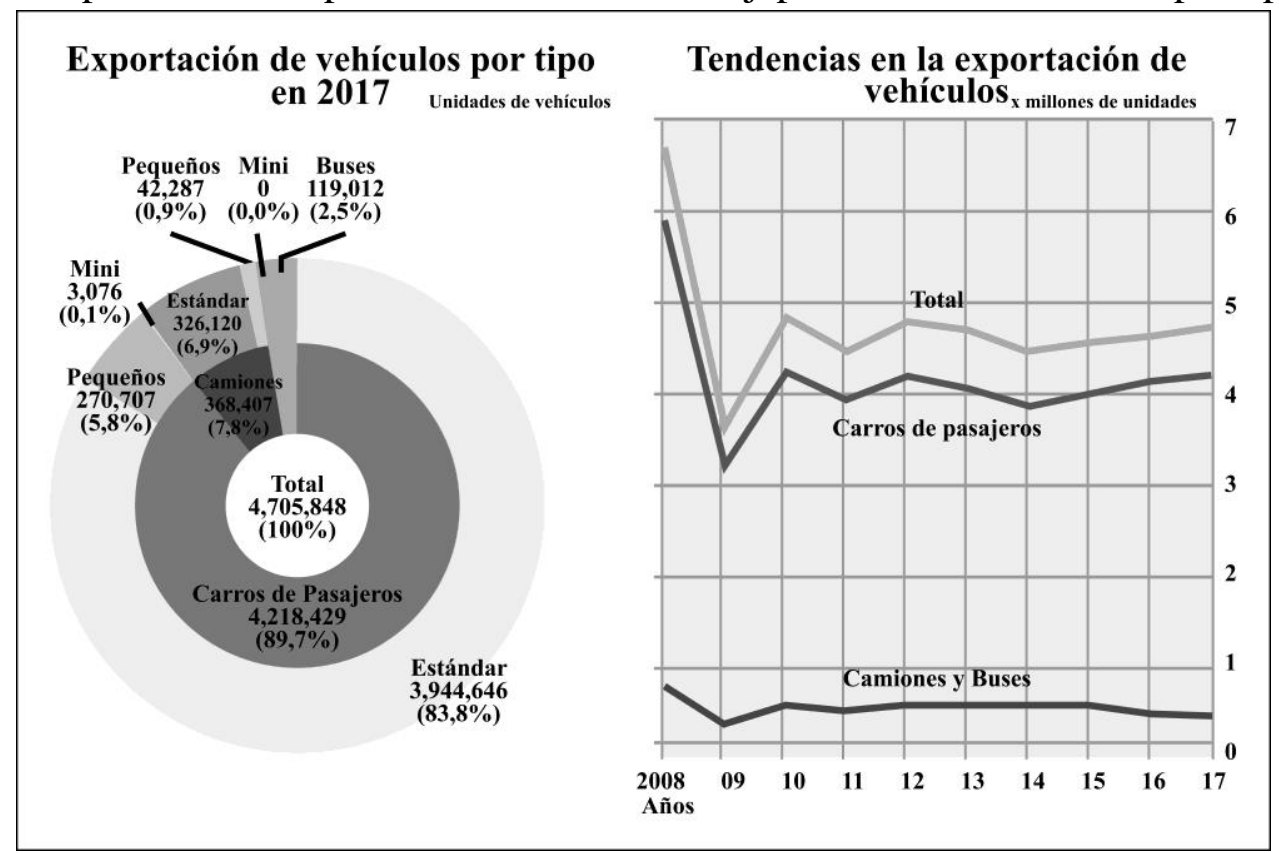

Fuente: Industria del motor en Japón 2018 en base a (Japan Automobile Manufacturers Association, Inc, 2018). 
No obstante, el mismo reporte a más de evidenciar el crecimiento de las exportaciones a partir del año 2009 a 2017, se puede observar la "baja" producida entre el año 2008 a 2009, y a pesar de observar una mejora a partir del 2010, no se alcanza los niveles del año 2008, manifestando un cambio en el comportamiento del sector.

\section{China: Un competidor de clase mundial}

En un mundo cambiante y con un mercado en evolución se generan las condiciones que favorecen la aparición o desarrollo de nuevos participantes que buscan adaptarse de mejor manera a los requerimientos de un sector en constante transformación. Desde unos años atrás China se ha convertido en el principal competidor tanto de los países fabricantes de vehículos a nivel internacional, así como de las tradicionales marcas posicionadas en las preferencias de los consumidores. Un estudio realizado por la Organización Internacional del Trabajo (OIT) en el año 2005 ya daba cuenta de esta realidad señalando que “... la producción en China ha aumentado más del 250 por ciento desde 1997 (ver tabla 1) mientras que en otros países se ha estancado" (Organización Internacional del Trabajo, 2005); extraído del estudio, la siguiente tabla presenta la información de la producción de la industria automotriz China, siendo evidente el constante incremento de producción de este sector empresarial. Además la gráfica 6 muestra los niveles de crecimiento por tipo de la producción de vehículos por tipo en el periodo 1997 2003

Tabla 1: Cantidad de vehículos producidos en China por tipo en el periodo 1997-2003 y porcentaje de crecimiento acumulado.

\begin{tabular}{|c|c|c|c|c|c|c|}
\hline \multicolumn{7}{|c|}{ Producción (Por unidades) } \\
\hline $\begin{array}{lll}\text { Tipos de } 1997 \\
\text { Vehículos }\end{array}$ & 1998 & 1999 & 2000 & 2001 & 2002 & 2003 \\
\hline $\begin{array}{l}\text { Automóviles } \\
\text { para } \\
\text { pasajeros }\end{array}$ & 507103 & 565366 & 604677 & 703521 & 1101696 & 2018875 \\
\hline $\begin{array}{l}\text { Vehículos } \\
\text { comerciales } \\
\text { ligeros }\end{array}$ & 1079872 & 1218870 & 1374489 & 1262226 & 801935 & 821111 \\
\hline $\begin{array}{l}\text { Camiones } \\
\text { pesados }\end{array}$ & 34829 & 38000 & 81950 & 309028 & 969358 & 1087000 \\
\hline Autobuses & 6025 & 7717 & 7953 & 59665 & 413815 & 516700 \\
\hline $\begin{array}{l}\text { Total de } 1579699 \\
\text { producción }\end{array}$ & 1627829 & 1829953 & 2069069 & 2334440 & 3286804 & 4443686 \\
\hline $\begin{array}{l}\text { Porcentaje } \\
\text { de aumento }\end{array}$ & $\begin{array}{l}103,05 \\
\%\end{array}$ & $\begin{array}{l}115,84 \\
\%\end{array}$ & $\begin{array}{l}130,98 \\
\%\end{array}$ & $\begin{array}{l}147,78 \\
\%\end{array}$ & $\begin{array}{l}208,07 \\
\%\end{array}$ & $\begin{array}{l}281,30 \\
\%\end{array}$ \\
\hline $\begin{array}{l}\text { de } \\
\text { producción } \\
\text { por año }\end{array}$ & año 1 & año 2 & año 3 & año 4 & año 5 & año 6 \\
\hline
\end{tabular}

Fuente: Tendencias de la industria automotriz que afectan a los proveedores de componentes en base a (Organización Internacional del Trabajo, 2005). 
Gráfico No6. Datos de la Producción y exportación de la industria automotriz China para el periodo $1997-2003$.

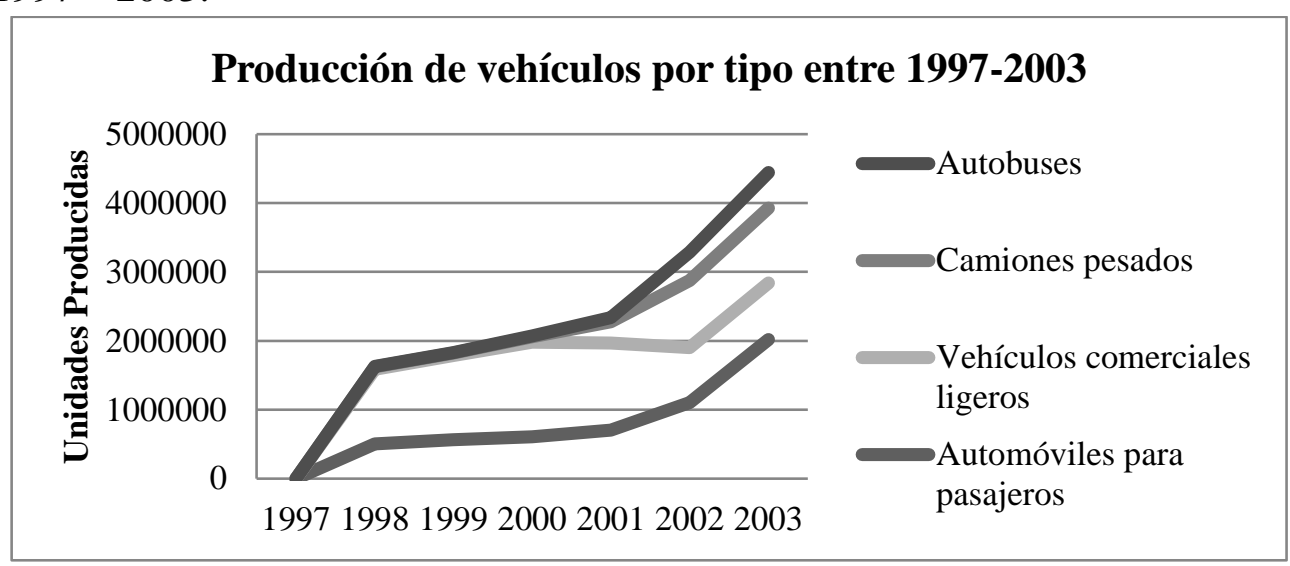

Fuente: Tendencias de la industria automotriz que afectan a los proveedores de componentes en base a (Organización Internacional del Trabajo, 2005).

Con los niveles de manufactura alcanzados, el país asiático se posicionó entre los principales productores en el mundo, para el año 2010 se había consolidado entre los diez países de mayor producción; con información del artículo «Estructura y recomposición de la industria automotriz mundial. Oportunidades y perspectivas para México 》 (Basurto Alva, 2013), se presenta la tabla 1 que muestra la cantidad de vehículos que cada una de las naciones del "top 10” produjeron en los años 2010 y 2012 según información de la Organización Internacional de Fabricantes de Vehículos de Motor.

Tabla 2

Estadísticas de producción mundial de vehículos de los diez principales países productores en años 2010 y 2012.

\begin{tabular}{|c|c|c|c|c|c|c|c|}
\hline \multirow[t]{2}{*}{$\mathrm{N}^{\mathrm{o}}$} & \multirow[t]{2}{*}{ País } & \multicolumn{2}{|c|}{ Automóviles 2010} & \multirow[t]{2}{*}{$\mathrm{N}^{\circ}$} & \multirow[t]{2}{*}{ País } & \multicolumn{2}{|c|}{ Automóviles 2012} \\
\hline & & Unidades & $\%$ & & & Unidades & $\%$ \\
\hline 1 & China & 18264667 & 23.53 & 1 & China & 19271808 & 22.90 \\
\hline 2 & Japón & 9625940 & 35.93 & 2 & $\begin{array}{l}\text { Estados } \\
\text { Unidos }\end{array}$ & 10328887 & 35.17 \\
\hline 3 & Estados Unidos & 7761443 & 45.93 & 3 & Japón & 9942721 & 46.98 \\
\hline 4 & Alemania & 5905985 & 53.54 & 4 & Alemania & 5649269 & 53.69 \\
\hline 5 & Corea del sur & 4271941 & 59.04 & 5 & Corea del sur & 4557738 & 59.10 \\
\hline 6 & Brasil & 3648358 & 63.74 & 6 & India & 4145194 & 64.02 \\
\hline 7 & India & 3536783 & 68.31 & 7 & Brasil & 3342617 & 67.99 \\
\hline 8 & España & 2387900 & 71.38 & 8 & México & 3001974 & 71.55 \\
\hline 9 & México & 2345124 & 74.40 & 9 & Tailandia & 2483043 & 74.50 \\
\hline 10 & Francia & 2227742 & 77.28 & 10 & Canadá & 2463732 & 77.47 \\
\hline & Subtotal & 59975883 & & & Subtotal & 65186993 & \\
\hline & Otros & 17634018 & 22.72 & & Otros & 18954216 & 22.52 \\
\hline & Total & 77609901 & 100.00 & & Total & 84141209 & 100.00 \\
\hline
\end{tabular}

Fuente: Estructura y recomposición de la industria automotriz mundial. Oportunidades y perspectivas para México en base a (Basurto Alva, 2013). 
Además, la producción China aportó a que en términos de bloques, Asia-Oceanía se convierta en la región predominante a nivel mundial con una producción de 40 millones 897 mil vehículos en el año 2010 para tener una participación del 52.7\% del mercado mundial (Basurto Alva, 2013), y de adicionalmente para ser en el mismo año la segunda economía mundial, el primer acreedor y el primer mercado del automóvil; así, la industria automotriz China aumentó en el espacio de diez años la fabricación de vehículos a casi cinco millones de unidades (Bracamonte Sierra \& Contreras Montellano, 2013).

China evolucionó, y con estrategias novedosas que incluyeron asociaciones con empresas del estado y empresas automotrices de prestigio como aliados estratégicos (ver tabla 3), le fueron útiles para posicionarse como el mayor productor del mundo con cerca de 13.8 millones de unidades para finales de la primera década del nuevo siglo (Rodríguez, 2013).

Tabla 3 Principales empresas automotrices chinas.

\begin{tabular}{lll}
\hline Empresas chinas & \multicolumn{2}{l}{ Socios extranjeros } \\
\hline $\begin{array}{l}\text { First Automobile Works Group Company } \\
\text { (FAW) }\end{array}$ & $\begin{array}{l}\text { Volkswagen, Toyota, } \\
\text { Mazda }\end{array}$ \\
$\begin{array}{l}\text { Dong Feng Motor Corporation (DFM) } \\
\text { Shanghái Automotive Industry }\end{array}$ & $\begin{array}{l}\text { Citroën } \\
\text { General } \\
\text { Volkswagen }\end{array}$ \\
Group Corporation (SAIC) & \\
Tianjin Automotive Industry Group & Daihatsu, Toyota \\
Gungzhou Auto Group & Honda \\
Beijing Automotive Industry Group & Daimler-Chrysler \\
Changan Automobile & Suzuki \\
Brilliance China Automotive & BMW \\
\hline
\end{tabular}

Fuente: La Industria Automotriz: Desarrollos en China y sus implicancias para Latinoamérica en base a (Kamiya \& Ramírez, 2004).

En la parte final de la década siguiente $\ll 2010$ a $2020 \gg$ se mantiene la tendencia, en mayo del año 2014 la revista especializada de negocios y finanzas FORBES se hacía eco de la publicación del ranking mundial de la Organización Internacional de Constructores de Automóviles (OICA) que divulgaba los 10 países con mayor producción de vehículos (ver tabla 4) de los 40 que la integran, ubicando a China como el país de mayor producción de vehículos con 22,11 millones de unidades y un crecimiento del $14,8 \%$.

Tabla 4 Ranking mundial de los diez países con mayor producción de vehículos

\begin{tabular}{lllll}
\hline Países & $\begin{array}{l}\text { Millones } \\
\text { vehículos }\end{array}$ & $\begin{array}{c}\text { de } \\
\text { Crecimiento } \\
\text { Variación }\end{array}$ \\
\hline 1 & China & 22.11 & $14.8 \%$ \\
2 & Estados Unidos & 11.04 & $6.9 \%$ \\
\hline 3 & Japón & 9.6 & $-3.1 \%$ \\
4 & Alemania & 5.7 & $1.2 \%$ \\
5 & Corea del Sur & 4.5 & $-0.9 \%$ \\
6 & India & 3.8 & $-7.0 \%$ \\
7 & Brasil & 3.7 & $9.9 \%$ \\
\hline
\end{tabular}




\begin{tabular}{llll}
\hline 8 & México & 3.0 & $1.7 \%$ \\
9 & Tailandia & 2.5 & $4.3 \%$ \\
10 & Canadá & 2.3 & -3.4 \\
\hline
\end{tabular}

Fuente: Los 10 países con mayor producción de autos en el mundo en base a (Meza Orozco, 2014).

Dos años más tarde la Agencia EFE señalaba que "la producción en la región asiática ha sido una "historia de éxito continuo" en los últimos doce años, con un fuerte crecimiento y con ventas que se duplicaron en 2016" (Agencia EFE, 2017), superando ampliamente la producción de sus competidores más cercanos como lo muestra la gráfica 7 .

Gráfico 7 Mayores países productores de vehículos en el 2016.

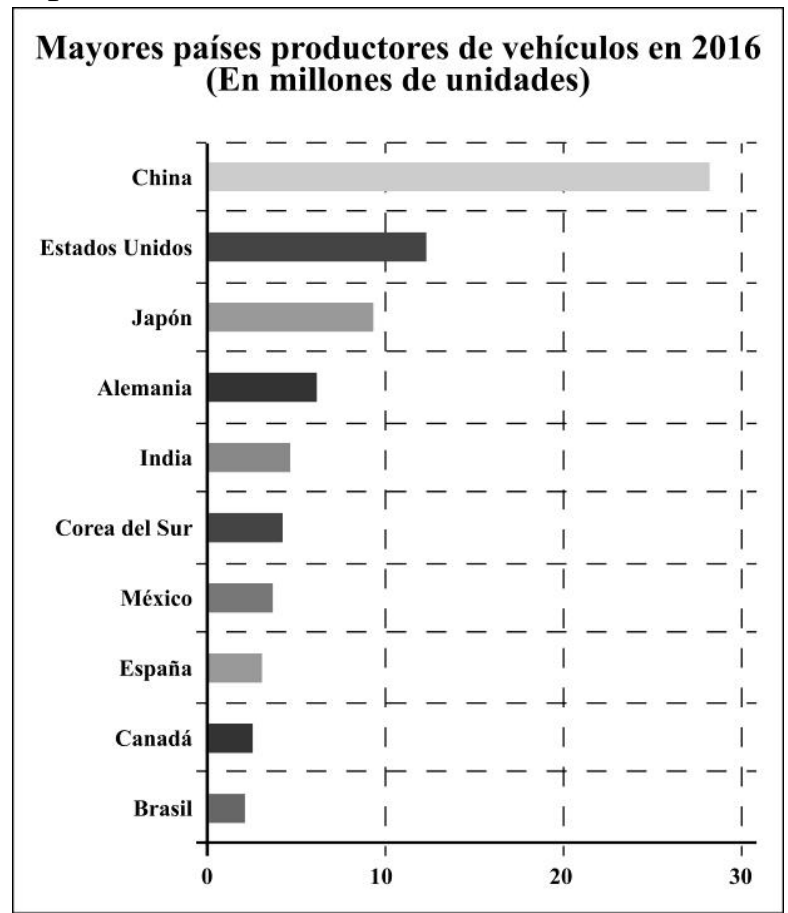

Fuente: Reorganización de la industria automotriz mundial en base a (Calderón, 2017).

La industria automotriz mundial ha evolucionado, su transformación a lo largo de alrededor de 130 años de historia es indiscutible, en particular desde los años cincuenta en que la mayor producción de vehículos se trasladó desde los países que motivaron su invención «del automóvil 》 y la extendieron 《la industria〉》, a países con economías en desarrollo (Calderón, 2017) que gracias a sus estrategias, apoyo estatal y adecuada lectura de las condiciones del entorno actual posicionaron a los productores asiáticos y en particular chinos como las nuevas potencias del sector automotriz, esto se puede observar en la gráfica 8 que muestra como la producción de vehículos norteamericanos (barra de color rojo) ha decrecido con el pasar del tiempo desde niveles del orden del $80 \%$ hasta llegar al 20\% en el año 2016, mientras que la producción de los países asiáticos (China, Japón-República de Corea y Otros Asia) de prácticamente no existir en 1950 ha llegado a tener más del 50\% de la producción mundial para el 2016. 
Gráfico No.8 Traslado de la Producción automotriz por países y regiones en el periodo 19602016.

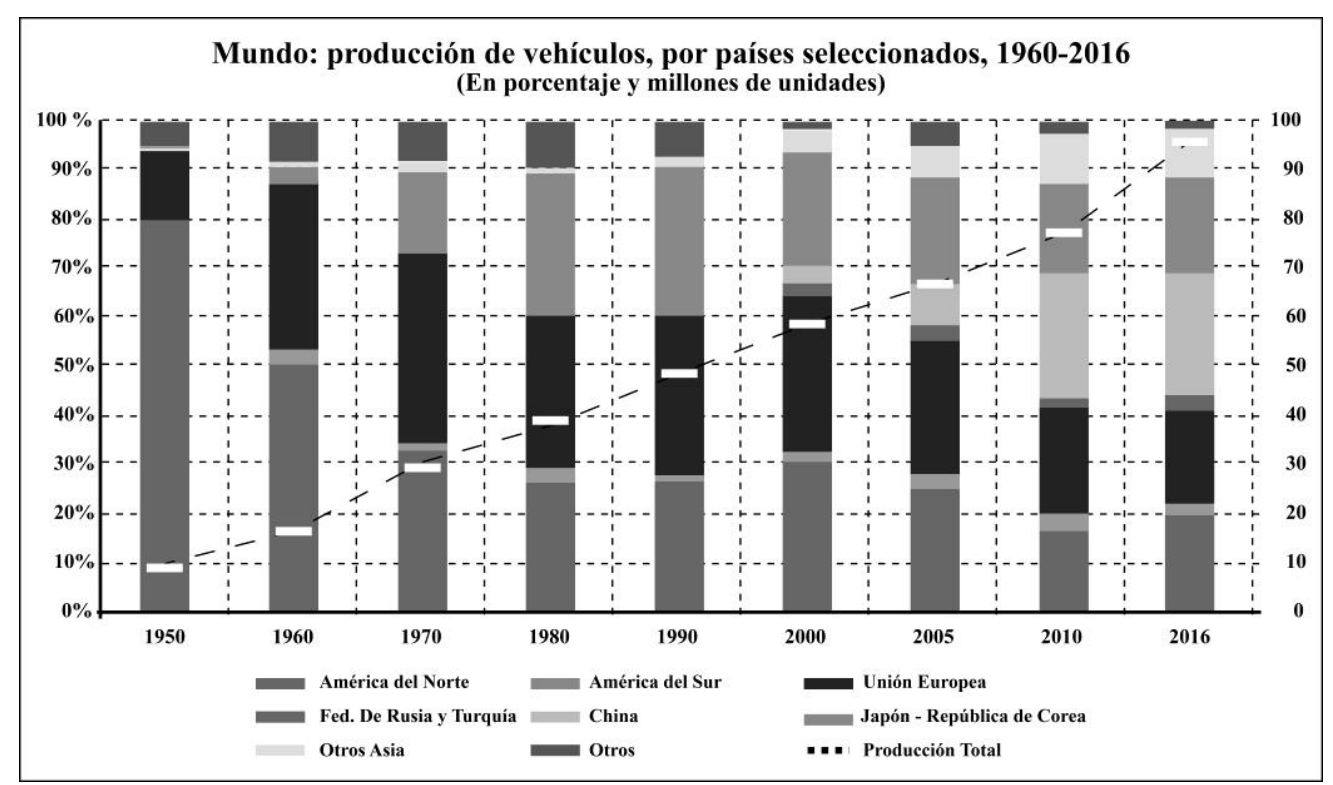

Fuente: Reorganización de la industria automotriz mundial en base a (Calderón, 2017).

Es evidente que la industria automotriz es fluctuante, su estabilidad obedece a varios factores que no siempre son favorables para los empresarios ni para los clientes (Parra \& Castellanos, 2015), sin embargo y hasta el momento la preferencia de los consumidores por los autos de los fabricantes chinos sigue en aumento (América Economía, 2012), son diversos los factores que orientan el gusto del consumidor por un tipo de vehículo en particular, provocando cambios en la industria y convirtiéndola en uno de los sectores más dinámicos de la era moderna (Suárez, 2010) y que en la actualidad han encontrado en Latinoamérica un terreno fértil en donde expandir su producción, ventas y posicionamiento (América Economía, 2012).

\section{Ecuador, un mercado en adaptación a las tendencias del sector automotriz mundial.}

La compra de un vehículo es un anhelo de los ecuatorianos, quienes destinan en promedio el $14,60 \%$ de sus ingresos 《rubro de transporte》 para el efecto (Instituto Nacional de Estadísticas

y Censo INEC, 2012), superado solo por el gasto en alimentación que con el 24,40\% ocupa el primer lugar; este rubro supera incluso al presupuesto de los hogares europeos, que reservan de media el $12,5 \%$ de su consumo total al gasto en transporte (Observatorio Cetelem, 2015). Este comportamiento se ha mantenido estable a lo largo de los últimos años; pues y a pesar de las distintas crisis presentadas en el país (BBC News, 2019), el crecimiento del parque automotor continua al alza, incrementando en más de 1,4 millones de unidades los vehículos que actualmente circulan a nivel nacional, esto solo en la última década (El Comercio, 2019); según datos reportados por el Instituto Nacional de Estadísticas y Censos (INEC) en el año 2015, en Ecuador se registró un aumento del 57\% más que lo registrado en el 2010, en este periodo se pasó de 1'226.349 a 1'925.368 vehículos motorizados que se matricularon en país (Instituto Nacional de Estadística y Censos INEC, 2016). Como dato adicional, en el Anuario Estadístico de Transporte 2018 presentada por el INEC el 1 de noviembre del 2019, confirma que el sector automotriz sigue siendo uno de los sectores económicos más prósperos en la actualidad 
(Tecniseguros, 2019). Esta situación se da en el país a pesar del descenso de ventas de vehículos a nivel regional, el informe de la Asociación de Empresas Automotrices del Ecuador (AEADE) del mes de octubre señala que "durante el mes de septiembre del año 2019 el mercado automotor regional reportó un decrecimiento del 1,3\% en sus ventas al compararlo con septiembre del año anterior..." (AEADE, 2019). Esta contraste en la información nacional versus la regional supone un comportamiento estable del consumidor ecuatoriano que sigue considerando la compra de un vehículo como parte importante de su presupuesto.

Sin embargo, las cifras globales no dan cuenta del cambio del comportamiento del consumidor, el que motivado por factores socioeconómicos ha modificado sus preferencias a la hora de adquirir un vehículo, originando la aparición de nuevas condiciones y actores en el mercado automotriz ecuatoriano. A pesar de existir en el país oferta de vehículos ensamblados a nivel local, el consumidor ecuatoriano muestra preferencia por los vehículos del exterior, pues 7 de cada 10 vehículos vendidos en el 2018 son importados; en los últimos años la participación de la industria automotriz ecuatoriana ha caído de manera sostenida, desde el 47,4\% en los primeros ocho meses de 2016 hasta el 26,7\% en igual período de este año (La Hora, 2019). Por otro lado, los vehículos fabricados en el exterior que ingresan con condiciones de acceso preferenciales han generado en el último año cambios de comportamiento en el mercado local; de este modo "los autos importados de destinos con los que Ecuador tiene acuerdos comerciales, conforme más reducen el porcentaje de aranceles que deben pagar para entrar al país se vuelven más competitivos y despiertan mayor interés entre los compradores" (Revista Líderes, 2018). Desde los primeros vehículos comercializados en el país hasta nuestros días las marcas norteamericanas han gozado de la preferencia de los consumidores (ver tabla 5), en particular los vehículos de General Motors GM específicamente Chevrolet «comportamiento similar al mercado global», la gráfica (9) muestra que los compradores ecuatorianos la prefieren.

Tabla 5 Ranking de participación de ventas por marcas de vehículos en Ecuador en 2019

\begin{tabular}{ll}
\hline Marca & Participación \\
\hline Chevrolet & $33,1 \%$ \\
\hline Otras Marcas & $17,0 \%$ \\
Kia & $16,8 \%$ \\
Hyundai & $9,9 \%$ \\
Great Wall & $6,1 \%$ \\
Toyota & $5,8 \%$ \\
Nissan & $3,6 \%$ \\
Hino & $3,0 \%$ \\
Chery & $2,4 \%$ \\
Ford & $2,3 \%$ \\
Total & $100,0 \%$ \\
\hline
\end{tabular}

Fuente: Segundo año de recuperación del sector automotor ecuatoriano en base a (Auto Magazine Ecuador, 2019). 
Gráfico 9 Distribución de la participación de ventas por marcas de vehículos en Ecuador en 2019.

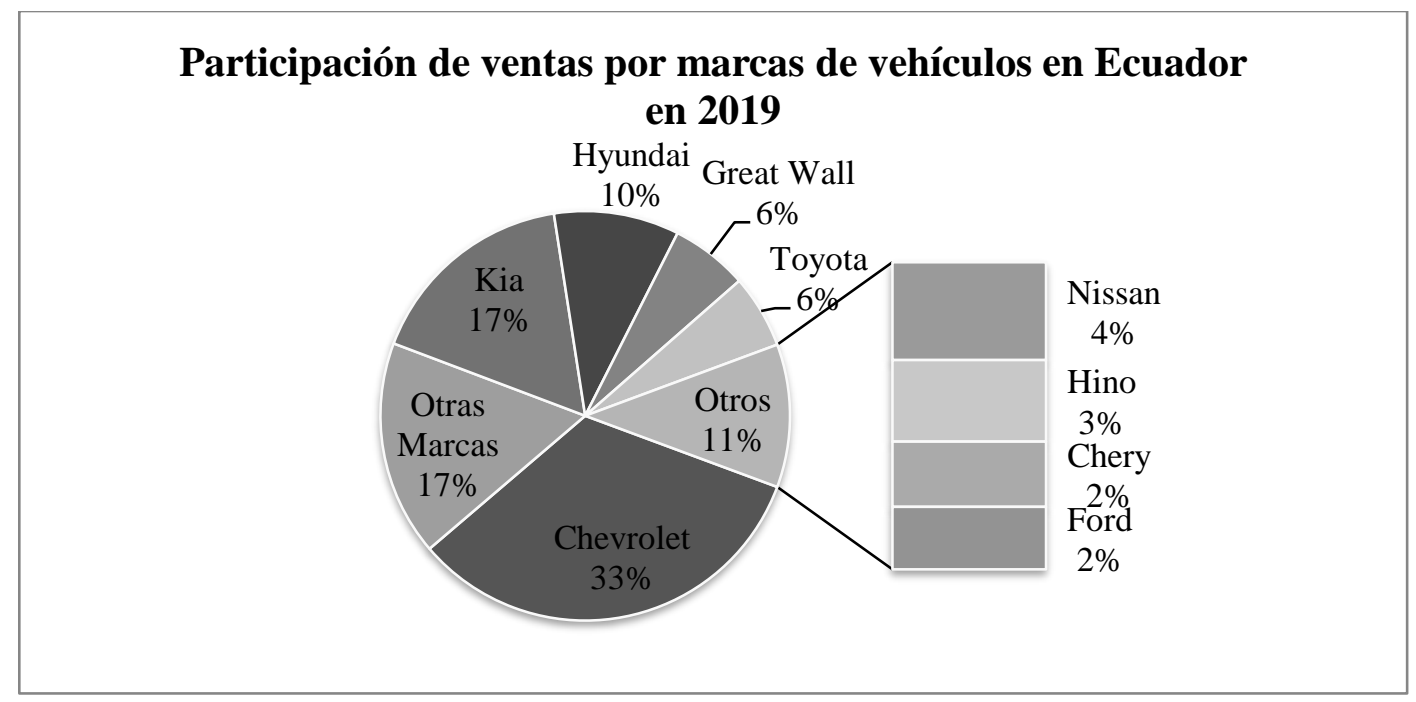

Fuente: Segundo año de recuperación del sector automotor ecuatoriano en base a (Auto Magazine Ecuador, 2019).

Cabe mencionar que la marca Chevrolet a pesar de mantener el liderazgo del mercado, su participación del 33,1\% en el año 2018 es significativamente inferior al 50\% del año 2015, debido a que ahora existe una mayor competencia, especialmente de marcas asiáticas (Auto Magazine Ecuador, 2019), tan solo en el 2018 ingresaron 15 nuevas marcas de vehículos, de ellas 11 son de procedencia china (Revista Ekos, 2019).

Al igual que en el contexto internacional, los vehículos originarios de la China se están posicionado en el liderazgo de ventas en el Ecuador; El Universo, uno de los diarios de mayor difusión afirma que el país "tiene un mercado automotor en el cual las marcas provenientes de China aumentan su participación e importancia con el paso de los años” (El Universo, 2019), entrevistado por este mismo medio, David Molina director ejecutivo de Cámara de la Industria Automotriz Ecuatoriana (CINAE) manifiesta que: "La industria ha perdido participación de mercado de una manera importante. Si sigue las tendencias del mercado, en un momento determinado las marcas 《que se importan desde» chinas van a liderar el mercado" (El Universo, 2019), ya en este 2019 tres marcas chinas se ubican entre las 10 más vendidas, demostrando que las "marcas originarias del gigante asiático son las que más crecimiento han tenido en el último año, con variaciones superiores a las del 100\%" (Revista Ekos, 2019), la tabla (6) que se muestra a continuación presenta las estadísticas de ventas de los años 2017 y 2018, las unidades vendidas y la variación de un año a otro; además en la gráfica 10 se muestra la significativa diferencia de crecimiento entre estos dos años de las ventas de marcas hasta hace poco desconocidas en el medio local como Soueast (792\%), JAC (255\%), Fotón (173\%) y Chery (106\%) respecto del resto de marcas ofertadas por los concesionarios a nivel nacional, incluso muy superior a marcas tradicionales como las norteamericanas Chevrolet y Ford, o las japonesas 
Toyota, Nissan y Mazda; por otro lado, marcas con años de comercialización en el país como Mitsubishi y Fiat muestran decrecimiento en sus ventas evidenciando que el mercado nacional ha cambiado.

Tabla 6 Cantidad de ventas de vehículos y sus variaciones entre 2107 a 2018 por marcas.

\begin{tabular}{|c|c|c|c|c|}
\hline Ranking & Marca & $\begin{array}{l}2017 \\
\text { (unidades) }\end{array}$ & $\begin{array}{l}2018 \\
\text { (unidades) }\end{array}$ & Variación \\
\hline 1 & Chevrolet & 41101 & 45605 & $11 \%$ \\
\hline 2 & $\mathrm{Kia}$ & 18223 & 23141 & $27 \%$ \\
\hline 3 & Hyundai & 9443 & 13568 & $44 \%$ \\
\hline 4 & Great Wall & 6792 & 8380 & $23 \%$ \\
\hline 5 & Toyota & 4804 & 7947 & $65 \%$ \\
\hline 6 & Nissan & 3568 & 4969 & $39 \%$ \\
\hline 7 & Hino & 3310 & 4154 & $25 \%$ \\
\hline 8 & Chery & 1614 & 3330 & $106 \%$ \\
\hline 9 & Ford & 2541 & 3175 & $25 \%$ \\
\hline 10 & JAC & 866 & 3075 & $255 \%$ \\
\hline 11 & Mazda & 1959 & 2737 & $40 \%$ \\
\hline 12 & Volkswagen & 1889 & 2626 & $39 \%$ \\
\hline 13 & Renault & 1953 & 2298 & $18 \%$ \\
\hline 14 & Peugeot & 481 & 1348 & $180 \%$ \\
\hline 15 & Citroën & 685 & 957 & $40 \%$ \\
\hline 16 & Soueast & 101 & 901 & $792 \%$ \\
\hline 17 & Changan & 8 & 820 & $0 \%$ \\
\hline 18 & Zotye & 572 & 807 & $41 \%$ \\
\hline 19 & Fotón & 291 & 793 & $173 \%$ \\
\hline 20 & $\begin{array}{l}\text { Mercedes } \\
\text { Benz }\end{array}$ & 441 & 614 & $39 \%$ \\
\hline 21 & DFSK & 328 & 512 & $56 \%$ \\
\hline 22 & Mitsubishi & 492 & 478 & $-3 \%$ \\
\hline 23 & Faw & 329 & 473 & $44 \%$ \\
\hline 24 & Shineray & 0 & 399 & $0 \%$ \\
\hline 25 & Jeep & 265 & 321 & $21 \%$ \\
\hline 26 & Fiat & 356 & 279 & $-22 \%$ \\
\hline 27 & BYD & 307 & 272 & $-11 \%$ \\
\hline 28 & Donsgfeng & 168 & 258 & $54 \%$ \\
\hline 29 & BMW & 148 & 257 & $74 \%$ \\
\hline
\end{tabular}

Fuente: Los 10 países con mayor producción de autos en el mundo en base a (Meza Orozco, 2014). 
Gráfico 10 Variaciones de ventas de vehículos por marca entre 2107 a 2018.

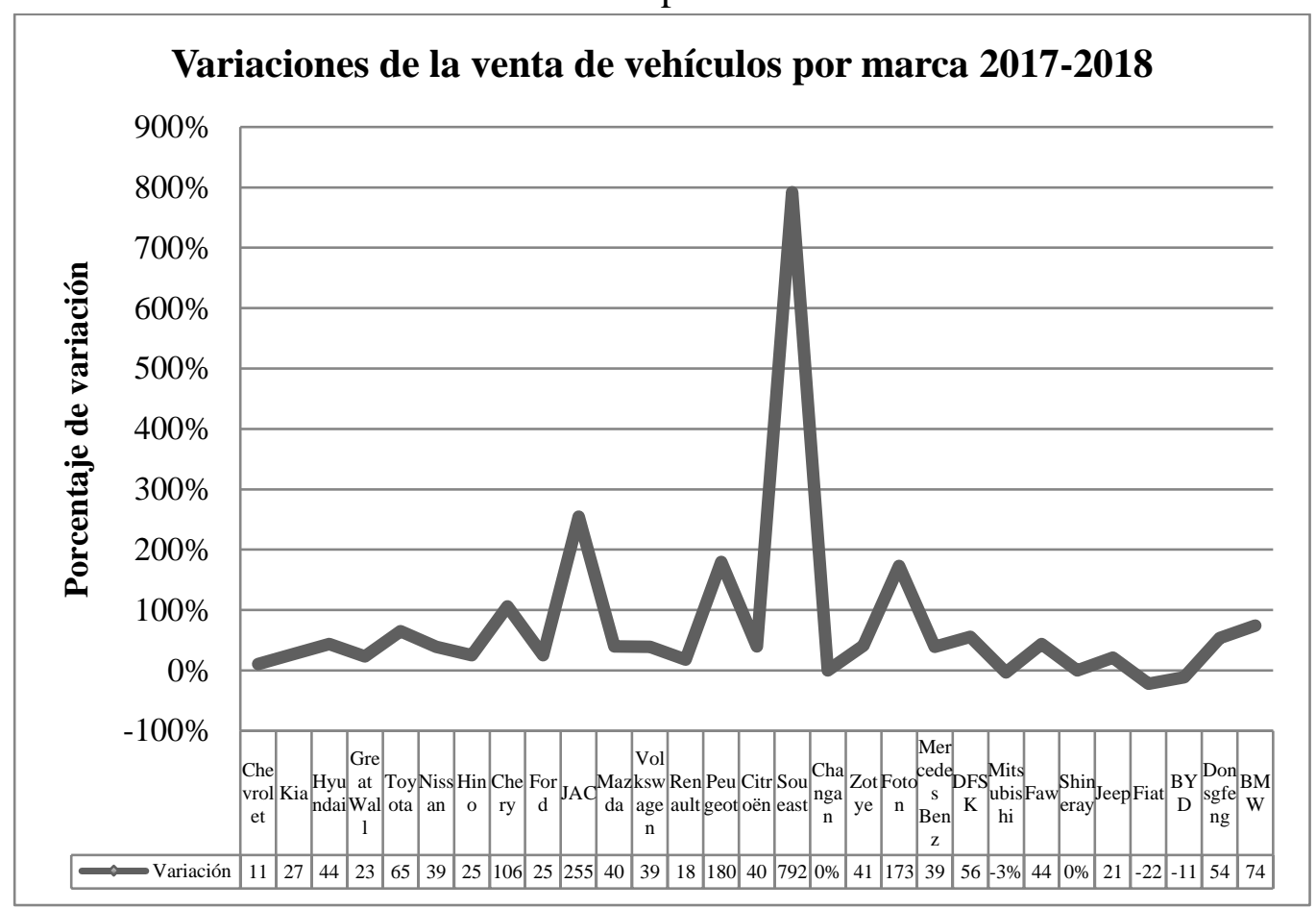

Fuente: Los 10 países con mayor producción de autos en el mundo en base a (Meza Orozco, 2014).

Entre los aspectos más relevantes del crecimiento de ventas de los vehículos "chinos" y la preferencia de compra por parte de los consumidores ecuatorianos están características como la comodidad y diseño según Juan Francisco Baca, gerente comercial de Go Motors, mientras que Sebastián Pérez, gerente comercial de GAC Motor asegura que se debe a los precios y los diseños aerodinámicos atractivos (El Comercio, 2019); estas afirmaciones coinciden en el precio como una de las razones por los que el consumidor se decide por un producto en particular, considerando a este último como el criterio de compra universal (Observatorio Cetelem, 2015), así lo afirma el estudio realizado por el Observatorio Cetelem en catorce países.

Respecto de los diseños, es importante mencionar que los fabricantes chinos han estado inmersos en problemas legales y acusaciones de plagio, pues muchos de los modelos de los fabricantes del país asiático son "copias" de modelos de marcas norte americanas y europeas, modelos que gozan de aceptación y preferencia de los consumidores a precios inferiores (Amadoz \& Herráez, 2017), esto junto a las ineficientes medidas de protección a la propiedad intelectual en el país, con procesos judiciales externadamente lentos (Amadoz \& Herráez, 2017) y con proteccionismo por parte del gobierno (BBC News, 2015) que dificultan las acciones que en defensa pudieran ejercer los fabricantes afectados.

Otro de los factores por los cuales los vehículos de fabricación china tienden a ser preferidos por los consumidores y que se constituye en un valor agregado para los consumidores es el nivel de equipamiento que poseen, según el Diario el Clarín, estas características son la carta de 
presentación de los modelos chinos que se basaban en precios tentadores a cambio de productos muy bien equipados (Clarín, 2018), el portal Autocosmos en su análisis de los autos chinos comercializados en México y al hablar sobre el modelo JAC SEI 7 indica que es "capaz de rivalizar contra algunas de las mejores SUV compactas del momento, tanto por equipamiento de confort y seguridad, como desempeño" (Ponce, 2019).

Pero no solo sus modelos se presentan a "tono" con las tendencias del mercado sino también sus fabricantes, los cuales buscan posicionarse como líderes en las nuevas prácticas empresariales y de producción acorde los principios de responsabilidad social y ambiental, esto coadyuva a mejorar y elevar la reputación e imagen empresarial, aspectos también valorados por los consumidores. El portal web de Changan Automobile Ecuador presenta a la empresa con proyección a ser la número 1 en investigación y desarrollo en China al contar con más de 5.000 patentes y 110 premios por nuestros proyectos de última generación (Changan Automobile, s.f.), sus vehículos están equipados con tecnología de punta para brindar mayor comodidad y servicio a los usuarios (Changan Automobile, s.f.), todo esto sin descuidar el objetivo de cuidar del medio ambiente como prioridad para Changan.

Con los constructores chinos posicionados en la cúspide de la producción y comercialización de vehículos a nivel internacional, el mundo se prepara para cambios en las estrategias de diferentes constructores con apoyo de sus países que buscarán recuperar competitividad y preferencia de los consumidores, este artículo no solo ha cumplido con su objetivo de presentar la evolución histórica del sector industrial automotriz a lo largo 130 años de existencia y como ha cambiado el liderazgo en uno de los sectores más dinámicos de la economía; sino que además abre un debate sobre la implicaciones que pudieran tener las estrategias implementadas en el comportamiento del sector, las consecuencias en la generación de empleo y desarrollo de la economía en los países exportadores e importadores, la afectación a la industria nacional, las transformaciones en función de nuevas soluciones de movilidad urbana que podrían afectar las producción y comercialización de vehículos entre otras perspectivas del tema que pudieran ser abordas.

\section{Conclusiones}

- La invención del automóvil y su posterior fabricación con fines comerciales dieron inicio a una industria que con el pasar de los años se convertiría en uno de los factores de desarrollo y crecimiento más importantes de las sociedades del siglo XX. Las distintas marcas, con sus aportes e innovación permanente trasformaron al vehículo hasta convertirlo en parte fundamental en la vida de seres humanos y de todo el andamiaje de la sociedad actual, que ha encontrado en los sistemas de transporte el sostén del funcionamiento de la vida moderna.

- De esta forma, el mundo ha sido testigo de cómo varios países han liderado las tendencias y volúmenes de exportaciones vehiculares hacia todo el mercado global; con el antecedente de encontramos en un mundo cambiante por naturaleza, y con los diferentes sucesos de impacto internacional ocurridos en la primera mitad del siglo XX como las guerras mundiales; o las distintas crisis presentadas en la segunda mitad del mismo siglo 
como resultado de la globalización y la economía de mercado ${ }^{6}$, que generaron las condiciones para que el liderazgo alcanzado desde los primeros años del siglo 1900 por las empresas automotrices norteamericanas como Ford, General Motors y Chrysler que llegaron a sumar más de sesenta años de hegemonía, se transfiera a un país como Japón que apostando a la eficiencia y el cambio de paradigmas en las políticas de gobierno a partir de la fin de la segunda guerra mundial, le valieron para ubicarse en el primer lugar de la producción para el inicio del siglo XXI; sin embargo, mientras estas dos naciones se disputaban este liderazgo mundial, China irrumpió el mercado con mucha fuerza y produciendo vehículos de bajo costo que redundó en un bajo precio de venta, con modelos que presentan similitudes estéticas a aquellos modelos de marcas reconocidas tanto americanas como europeas ya posicionadas en la preferencias de los consumidores, y dotando a los vehículos de artilugios de alta tecnología solo destinados a vehículos de alta gama, se ubicó en el liderato mundial del sector. No obstante, ni Estados Unidos ni Japón renuncian a retomar sus posiciones, es por eso que el mercado del sector automotriz se prepara para una nueva etapa que merece ser analizada para estar preparados para cambios que influirán en el desarrollo de la vida como la conocemos.

\section{Referencias Bibliográficas}

Agencia EFE. (2017). La producción mundial de vehículos creció un 5 \% en 2016, según la OICA. Recuperado de https://www.efe.com/efe/espana/economia/la-produccionmundial-de-vehiculos-crecio-un-5-en-2016-segun-oica/10003-3201572\#.

Álvarez, R. B. (2013). Estructura y recomposición de la industria automotriz mundial. Oportunidades y perspectivas para México. 10 (30), 75-92.

Amadoz, S., \& Herráez, M. (2017). Los 13 coches que las marcas chinas han plagiado con mayor descaro. El Motor.

América Economía. (2012). Recuperado de https://www.americaeconomia.com/negociosindustrias/fabricantes-de-autos-chinos-aceleran-su-expansion-por-latina.

Anything About Cars. (s.f.). Recuperado de https://www.anythingaboutcars.com/1950scars.html.

Arenas Rosales, R., Vera Sanjuán, K. É., \& Soto Bustos, E. (2010). La caída del imperio automotriz estadounidense. Espacios Públicos, 13 (27), 96-112.

Arruda, M. (2003). Socioeconomía Solidaria. En A. Cattani, P. Peixoto de Albuquerque, E. Mance, M. Baquero, A. Cotera Fretell, H. Ortiz Roca, y otros, La Otra Economía (págs. 373-387). Porto Alegre, Brasil: Editora Veraz Ltda.

Asociación de Empresas Automotrices del Ecuador, AEADE. (2019). Recuperado de https://www.aeade.net/wp-content/uploads/2019/11/boletin-regional-31-resumido.pdf.

Auto Magazine Ecuador. (2019). Recuperado de https://automagazine.ec/segundo-ano-derecuperacion-del-sector-automotor-ecuatoriano/.

Auto México. (2019). Recuperado de https://automexico.com/industria/historia-del-automovily-su-evolucion-aid1968.

\footnotetext{
${ }^{6}$ La economía de mercado capitalista está fundada en la creencia de que el mercado es capaz de auto-regularse para el bien de todos, y que la competencia es el mejor modo de relación entre los actores sociales. Arruda (2003).
} 
Basurto Alva, R. (2013). Estructura y recomposición de la industria automotriz mundial. Oportunidades y perspectivas para México. Economía UNAM, 10 (30), 75-92 .

BBC News. (2015). Las 5 copias de autos más flagrantes y curiosas de China. Recuperado de https://www.bbc.com/mundo/noticias/2015/11/151123_economia_china_autos_5_copia s_flagrantes_ms.

BBC News. (2019). Recuperado de https://www.bbc.com/mundo/noticias-49978717.

Blanco Jiménez, M., Guerra Moya, S., \& Villalpando Cadena, P. (2007). La Evolución de la Industria del Sector Automotriz en Japón, Crecimiento de las Empresas Japonesas. Recuperado de http://gitmexico.com/acacia/busqueda/pdf/P27T5.pdf.

Boncheva, A. I., Michel, Á. L., Becerra, M. L., Mendoza Martínez, E., Delgado, J. E., \& Prieto, C. (2016). Las políticas gubernamentales de ciencia y tecnología en el Asia Pacífico en la posguerra: los casos de Japón y Corea del Sur. PORTES, Revista Mexicana de Estudios sobre la Cuenca del Pacífico, 10 (20), 105-136.

Bracamonte Sierra, A., \& Contreras Montellano, O. (2013). Ciencia, tecnología e innovación para el desarrollo económico. Hermosillo, México: El Colegio de Sonora; Consejo Estatal de Ciencia y Tecnología (COECYT).

Calderón, Á. (2017). La reorganización de la industria automotriz mundial. Comisión Económica para América Latina y el Caribe, CEPAL. Ciudad de México: CEPAL.

Changan Automobile. (s.f.). Recuperado de https://changanecuador.com/quienes-somos/.

Clarín. (2018). Invasión china: ya son 12 las marcas de autos que venden modelos en el país. Recuperado de https://www.clarin.com/autos/marcas-autos-chinos-modelosofrecen_0_5y5gDON66.html.

Clothier, R., Fulton, N., \& Walker, R. (2008). Pilotless aircraft: the horseless carriage of the twenty-first century? Journal of Risk Research, 11 (8), 999-1023.

Daher, A. (2013). El sector inmobiliario y las crisis económicas. EURE, 39 (118), 47-76.

El Comercio. (2019). Recuperado de https://www.elcomercio.com/actualidad/parqueautomotor-ecuador-crecimiento-decada.html.

El País. (2008). Recuperado de https://elpais.com/economia/2008/04/23/actualidad/1208935988_850215.html.

El Universo. (2019). Recuperado de https://www.eluniverso.com/noticias/2019/11/06/nota/7591049/autos-producenensamblan-ecuador.

El Universo. (2019). Recuperado de https://www.eluniverso.com/noticias/2019/11/04/nota/7589138/autos-chinos-marcasecuador.

Faes, I. (2016). Recuperado de: https://www.eleconomista.es/legislacion/noticias/7741918/08/16/Un-coche-adaptadoes-un-bien-de-primera-necesidad.html.

García, D. (2012). La "Doctrina Obama", La Teoría de la "Guerra Limitada" y la Nueva Política Exterior de EEUU: ¿Hacia Una Política Neo-Nixoniana? Revista UNISCI (28), 145-153.

Hernández, J. (2007). Todo lo que debe saber sobre la Primera Guerra Mundial. Madrid, España: Ediciones Nowtilus S.L. 
Hernández, J. (2009). Breve historia de la Segunda Guerra Mundial. Madrid, España: Ediciones Nowtilus S.L.

Instituto Nacional de Estadística y Censos INEC. (2016). Recuperado de https://www.ecuadorencifras.gob.ec/el-parque-automotor-de-ecuador-crecio-57-encinco-anos/.

Instituto Nacional de Estadísticas y Censo INEC. (2012). Recuperado de https://www.ecuadorencifras.gob.ec//documentos/web-

inec/Estadisticas_Sociales/Encuesta_Nac_Ingresos_Gastos_Hogares_Urb_Rur_ENIGH U/ENIGHU-2011-2012/EnighurPresentacionRP.pdf.

Japan Automobile Manufacturers Association, Inc. (2018). The Motor Industry of JAPAN 2018. Tokyo: Public Relations Office, JAMA.

Kamiya, M., \& Ramírez, C. (2004). La industria automotriz: Desarrollos en China y sus implicancias para Latinoamérica. Journal of Economics, Finance and Administrative Science, 9 (17), 5-20.

La Hora. (2019). La industria automotriz ecuatoriana lleva 6 años de ventas decrecientes. Quito, Ecuador. Recuperado de https://www.lahora.com.ec/noticia/1102271317/la-industriaautomotriz-ecuatoriana-lleva-6-anos-de-ventas-decrecientes.

Lavarello, P., Bil, D., Vidosa, R., \& Langard, F. (2019). Reconfiguración del oligopolio mundial y cambio tecnológico frente a la agricultura 4.0: implicancias para la trayectoria de la maquinaria agrícola en Argentina. CICLOS en la historia, la economía y la sociedad, 26 (53), 163-193.

Lolas, J. (2019). Recuperado de https://www.laprimera.pe/tener-un-auto-una-necesidad/.

Marcas de Coches. (s.f.). Recuperado de https://marcasdecoches.org/todas-las-marcas-decoches/asiaticos/japoneses/.

Marco, J. L. (2002). Los precios de los automóviles importados en la España de los años veinte. Revista de Historia Industrial. Economía y Empresa, 22, 157-176.

Meza Orozco, N. (2014). Los 10 países con mayor producción de autos en el mundo. Forbes México.

Michael, M., \& Faustino, B. (2005). Informe sobre la industria automotriz mexicana. (CEPAL, Ed.) Serie Desarrollo Productivo (162).

Mortimore, M., \& Barron, F. (2005). Informe sobre la industria automotriz mexicana. Naciones Unidas, Comisión Económica para América Latina y el Caribe CEPAL. Santiago de Chile: Secretario de la Junta de Publicaciones, Sede de las Naciones Unidas.

Motor Historia. (s.f.). Recuperado de http://motorhistoria.com/historia-de-toyota.

Murakami, Y. (1995). Un análisis de la política exterior japonesa hacia el gobierno de Fujimori, desde la perspectiva interna del Japón. Agenda Internacional, 2 (4), 37-52.

Mustoe, H. (2004). Lo que la industria aprendió de la Primera Guerra Mundial. BBC News.

Nicolás, J. D. (2013). ¿Crisis económica, crisis financiera o crisis del sistema social global? Revista Española de Sociología (19), 125-140.

Observatorio Cetelem. (2015). El Observatorio Cetelem Auto 2015. Madrid: Cetelem.

Organización Internacional del Trabajo. (2005). Tendencias de la industria automotriz que afectan a los proveedores de componentes (Primera edición ed.). Ginebra, Suiza: Organización Internacional del Trabajo. 
Ortíz Villajos, J. M. (2001). Evolución histórica de la industria de equipos y componentes de automoción. Historia del sector del automóvil en España, Actas del VII Congreso de la Asociación de Historia Económica (págs. 19-21). Zaragoza: Universidad de Zaragoza.

Parra, P., \& Castellanos, W. (2015). El negocio de autos usados, víctima del efecto dominó. Gestión (255), 48-51.

Ponce, E. (2019). Recuperado de https://noticias.autocosmos.com.mx/2019/05/08/todos-losautos-chinos-que-se-venden-en-mexico-durante-2019.

Revista Ekos. (2019). Recuperado de https://www.ekosnegocios.com/articulo/las-marcas-deautos-mas-vendidas-en-ecuador

Revista Líderes. (2018). 7 de cada 10 vehículos vendidos en el 2018 son importados. (G. e. Comercio, Ed.) Quito, Ecuador.

Rodríguez, C. (2013). Oligopolio y competencia mundial en la industria automotriz. La emergencia del Toyotismo y la caída del Fordismo. Economía Informa, 383, 107-130.

Rosenthal, G. (4 de 2010). La crisis financiera y económica de 2008 y su repercusión en el pensamiento económico. Revista CEPAL, 29-39.

Ruíz, J. L. (2001). La evolución de la industria automovilística española, 1946-1999: una perspectiva comparada. Revista de Historia Industrial. Economía y Empresa (19-20), 133-163.

Statista. (2019). Recuperado de https://www.statista.com/statistics/199983/us-vehicle-salessince-1951/.

Statista. (2013). Recuperado de https://cdn.statista.com/statistics/204186/north-americavehicle-production-since-1951/.

Suárez, Y. C. (2010). Sector automotriz: reestructuración tecnológica y reconfiguración del mercado mundial. Paradigma económico 2.1, 2 (1), 24-52.

Tecniseguros. (2019).

Recuperado

de https://www.tecniseguros.com.ec/blog/vehiculos/estadisticas-de-autos/.

Toyocosta. (s.f.). Recuperado de http://www.toyocosta.com/blog/un-paseo-por-la-historia-detoyota/.

Univisión Communications Inc. (2016). Recuperado de https://www.univision.com/carros/historia-visual-de-la-publicidad-automotriz-desde1888-hasta-1919-fotos\#fff14e8b0000.

Ureta Icaza, S. (2009). Manejando por Santiago: Explorando el uso de automóviles por parte de habitantes de bajos ingresos desde una óptica de movilidad sustentable. EURE, 35 (105), 71-93.

Yáñez, C., \& Badia-Miró, M. (2011). El consumo de automóviles en la América Latina y el Caribe (1902-1930). El Trimestre Económico, 78 (310), 317-342.

\section{【Ciencia}




\section{PARA CITAR EL ARTÍCULO INDEXADO.}

Alarcón Parra, G. J., Centeno Parra, X., Villacrés Cáceres, O., \& Garrido Patrel, A. M. (2020). El liderazgo en la producción automotriz mundial: Una historia de cambio en los 130 años de existencia de la industria. ConcienciaDigital, 3(3.1), 252-274. https://doi.org/10.33262/concienciadigital.v3i3.1.1387

\section{Ciencia \\ LDigital}

El artículo que se publica es de exclusiva responsabilidad de los autores y no necesariamente reflejan el pensamiento de la Revista Conciencia Digital.

El artículo queda en propiedad de la revista y, por tanto, su publicación parcial y/o total en otro medio tiene que ser autorizado por el director de la Revista Conciencia Digital.
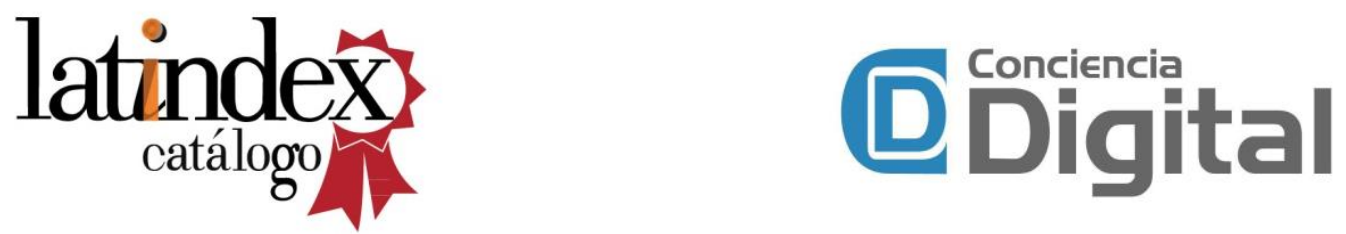